\title{
BERNARD VOUILLOUX, Image et médium. Sur une hypothèse de Pascal Quignard
}

\section{Laura Brignoli}

\section{OpenEdition}

\section{Journals}

Édition électronique

URL : http://journals.openedition.org/studifrancesi/15859

DOI : 10.4000/studifrancesi. 15859

ISSN : 2427-5856

\section{Éditeur}

Rosenberg \& Sellier

\section{Édition imprimée}

Date de publication : 1 décembre 2018

Pagination : $532-533$

ISSN : 0039-2944

\section{Référence électronique}

Laura Brignoli, " BernaRd vouIlloux, Image et médium. Sur une hypothèse de Pascal Quignard ", Studi Francesi [En ligne], 186 (LXII | III) | 2018, mis en ligne le 01 janvier 2019, consulté le 06 janvier 2021. URL : http://journals.openedition.org/studifrancesi/15859 ; DOI : https://doi.org/10.4000/ studifrancesi. 75859

Ce document a été généré automatiquement le 6 janvier 2021.

\section{(c) (i) (9)}

Studi Francesi è distribuita con Licenza Creative Commons Attribuzione - Non commerciale - Non opere derivate 4.0 Internazionale. 


\title{
BERNARD VOUILLOUX, Image et médium. Sur une hypothèse de Pascal Quignard
}

\author{
Laura Brignoli
}

\section{RÉFÉRENCE}

BERNARD VOUILLOUX, Image et médium. Sur une hypothèse de Pascal Quignard, Paris, Les Belles

Lettres, 2018, «Essais», $107 \mathrm{pp}$.

1 Une œuvre extrêmement complexe requiert-elle une analyse qui le soit autant? C'est une question qu'il faut se poser à propos de Pascal Quignard, dont l'œuvre ne cesse de susciter des lectures critiques très diverses: certaines, submergées par la richesse de l'œuvre, finissent par en épaissir le mystère au même moment où elles montrent des chemins possibles pour la traverser. Le livre de Bernard Vouilloux donne sa propre réponse en soulevant des questions qui ouvrent sur un horizon culturel très vaste et convoquent des savoirs élitistes. Affronter cette œuvre signifie pour Vouilloux se placer au même niveau de complexité que l'œuvre analysée. Il ne cherche pas moins un fil conducteur, qui semble mince mais qui se montre de plus en plus solide au cours de la lecture. Ce fil rouge est une image qu'il cristallise dans la figure mythique de Médée.

2 L'introduction s'ouvre sur un panorama complet de ce à quoi renvoie la notion d'image dans la culture occidentale (de la rhétorique à l'imagologie, de la politique à l'anthropologie, de l'histoire de l'art à la communication), et continue avec la fonction de l'image dans les différentes époques historiques. L'œuvre de Quignard est particulièrement efficace pour illustrer l'hypothèse de départ: «toute image, en tant qu'elle est image de ce qui est sans image, est un médium» (p.40). L'image est donc médium dans la mesure où elle concrétise une absence, donne forme à l'irreprésentable, ce «jadis» qui est le point de conjonction entre l'individu et l'espèce et qui permet aux êtres humains de communiquer. Dans Le sexe et l'effroi, Quignard lit la Médée d'Euripide à la lumière des fresques pompéiennes, qui lui sont pourtant postérieurs de cinq siècles. La lecture croisée (philologique et iconique) montre la 
valeur médiatrice de cette figure mythique qui finit par renvoyer, de façon encore assez cryptique à ce stade de l'analyse, à la scène primitive et où la naissance se joint à son contraire.

3 La récriture de ce mythe que Quignard fait dans le livret qui accompagne la danse de Carlotta Ikeda, en faisant appel à la philologie, reconstruit l'image non d'une sorcière, mais d'une chamane, c'est-à-dire de celle qui, en communiquant avec le corps et le mouvement, ouvre la voie vers les esprits. L'acte narratif, comme l'image-médium, fixe le moment qui précède son accomplissement, le moment chargé de toutes les possibilités: c'est le seul moyen pour figurer la pensée et Médée, en tant que figure de la méditation, est saisie justement dans l'instant qui précède sa décision de tuer ses enfants.

4 Les images ont une valeur assertive: elles ne parlent pas, ne nient pas, n'explicitent pas les rapports logiques. Mais, en tant que médiatrices, elles médusent. Pour Quignard ce pouvoir de fascination appartient aussi à l'acte de la lecture et d'une écriture justement définie par Michel Déguy comme «sidérante» dans la mesure où elle est assertive, érudite, asyndétique, affabulatrice, fragmentaire. C'est une écriture non argumentative qui ne cherche pas à convaincre par les moyens de la rhétorique, mais qui possède néanmoins une dimension argumentative qui inquiète. Chercher l'ethos de l'auteur dans les textes est une démarche inutile pour un écrivain comme Quignard, inévitablement destiné à projeter son ombre sur la longue période. Plus que les «schémas platement causalistes d'un déterminisme forcément réducteur», Vouilloux invite à considérer la "complexité des surdéterminations» qui apparaît dans les images représentées ou rêvées: «leur silence, leur caractère assertif, l'incertitude dans laquelle nous laisse l'absence de liens logiques, à quoi il conviendrait d'ajouter la neutralisation de la stratification temporelle dans un présent continu [...] est-ce un hasard si nous les retrouvons dans l'écriture même de Pascal Quignard?» (pp. 104-105). C'est ainsi qu'émerge un des sens d'une œuvre prodigieusement riche, à la fin d'un parcours parfois très complexe qui, seulement en ne cédant en rien à la facilité, parvient à en cerner un aspect important. 